\title{
Insulin-like growth factor (IGF)-I, IGF binding protein-3, and breast cancer risk: eight years on
}

\author{
Andrew G Renehan ${ }^{1}$, Michelle Harvie ${ }^{2}$ and Anthony Howell ${ }^{2}$ \\ ${ }^{1}$ Department of Surgery and ${ }^{2}$ Department of Medical Oncology, Christie Hospital NHS Trust, Wilmslow Road, Manchester M20 4BX, UK \\ (Requests for offprints should be addressed to A Renehan; Email: arenehan@ picr.man.ac.uk)
}

\begin{abstract}
Insulin-like growth factor (IGF)-I, and its main binding protein, IGFBP-3, are multi-functional regulatory peptides of cell growth and survival, attributes important for tumourigenesis. Following seminal work published in 1998, it has been hypothesised that circulating concentrations of these growth factors may be associated with cancer risk. Systematic reviews have reported that high normal range circulating levels of total IGF-I predict for pre- but not post-menopausal breast cancer. By contrast, associations with circulating IGFBP-3 have been inconsistent. A cumulative meta-analysis demonstrates that earlier reported positive associations between IGFBP-3 and pre-menopausal breast cancer risk now seem less clear as large-size cohorts are published. The reasons are complex and include differences in study design, lack of standardisation between assays, and variations in IGFBP-3 proteolytic activity - these are discussed in this commentary.
\end{abstract}

Endocrine-Related Cancer (2006) 13 273-278

Endocrinologists have long recognised the importance of growth hormone (GH)-dependent insulinlike growth factor (IGF)-I and its main binding protein, IGFBP-3 for growth and development. In 1998, determination of these circulating growth factors gained prominence in cancer epidemiology when investigators from the Health Professionals Study demonstrated that concentrations of IGF-I, measured in prospectively collected plasma, were positively associated, while concentrations of IGFBP-3 were inversely associated with the subsequent development of prostate cancer (Chan et al. 1998). A number of subsequent studies, but not all, supported the hypothesis of reciprocal associations for IGF-I and IGFBP-3 with other cancer sites including breast, colorectal and lung. Against this background, we sought to quantify these associations through systematic review and meta-regression using a search strategy up to December 2002 (Renehan et al. 2004). For breast cancer, our findings demonstrated that higher concentrations of total IGF-I were positively associated with an increased risk of pre-menopausal breast cancer (case-control and cohort studies combined: pooled odds ratio $=1.93(95 \%$ confidence interval $(\mathrm{CI})$ : $1.38,2.69)$ ), but contrary to expectations, we found that IGFBP-3 concentrations were positively associated with pre-menopausal breast cancer (combined studies: 1.96 (95\% CI: 1.28, 2.99)), and importantly, there was no evidence of statistical heterogeneity. Three subsequent systematic reviews, using slightly different approaches, came to the same conclusion that there were positive associations for both IGFI and IGFBP-3 for pre-menopausal breast cancer, and consistently demonstrated no association for either analyte for post-menopausal breast cancer (Fletcher et al. 2005, Renehan et al. 2005a).

Fletcher and colleagues (2005) also reviewed IGFI and IGFBP-3 polymorphisms, predominantly of the simple sequence type, and their associations with breast cancer risk. They concluded that any single polymorphism contributes modestly to variation in circulating IGF-I and IGFBP-3 concentrations and, in turn, only accounts for a small proportion of risk of breast cancer. More recently, a large tagging study using single nucleotide polymorphisms (SNP) reported that the $c$ allele of IGF-I SNPrs1520220 was associated with increased 
circulating IGF-I in females and an increased risk of breast cancer, and that the $a$ allele of IGFBP-3 SNP rs2854744 was associated with increased circulating IGFBP-3 but a decreased risk of breast cancer (Al-Zahrani et al. 2006). This study found no differences between pre- and post-menopausal breast cancer, and together with the apparent protective effect of IGFBP-3, is contrary to the findings of the afore-mentioned meta-analyses.

Several cellular actions of IGF-I favour tumour growth, as it is mitogenic, anti-apoptotic, pro-angiogenic, and increases cell migration in vitro (Renehan 2004), while low circulating IGF-I levels are associated with delayed onset of chemically and genetically induced mammary tumours in in vivo models (Wu et al. 2003). By contrast, IGFBP-3 may be bidirectional in terms of tumour behaviour. It may be anti-proliferative and pro-apoptotic, either through sequestration of the IGF-I ligand or through IGF-independent effects (Firth \& Baxter 2002), attributes thought to underlie why some epidemiological associations with cancer risk are inverse. However, IGFBP-3 action may be modulated through proteolytic enzymes and, in turn, cleaved IGFBP-3 fragments may either potentiate or inhibit tumour growth (Baxter 2001). Additionally, IGFBP3 demonstrates anti-apoptotic properties in anchorage-dependent growth in vitro (McCaig et al. 2002) and may activate proliferation-related signalling pathways in other cellular systems (Ricort \& Binoux 2004). However, these laboratory observations do not directly answer the question as to why the associations of IGF-I and IGFBP-3 are different for pre- vs post-menopausal breast cancer. Such findings may reflect the differential effects of IGF-I and IGFBP-3 on cell growth between pre- and post-menopausal breast tissues (Renehan et al. 2005b) and/or the complex inter-relationships between breast connective tissue, fat and epithelium with increasing age (Howell et al. 2005).

In this month's journal, two studies are reported expanding the epidemiological data on the associations between IGF-I, IGFBP-3 and breast cancer risk. The European Prospective Investigation into Cancer and Nutrition (EPIC) investigators (Rinaldi et al. 2006) report the largest cohort of women to-date with the endpoint of breast cancer; they report no associations in younger women using the baseline data but positive modest associations for IGF-I and IGFBP-3 in women developing cancer after the age of 50 years. Interestingly, the IGF-I association was attenuated after adjustment for IGFBP-3. At first glance, these results appear to contradict the main literature. However, there are important differences in the design and reporting of this study. First, the investigators analysed their results based on the division into above and below 50 years of age at the time of breast cancer diagnosis. From a glance at Table 1 in their paper, it is quite clear that this chronological division does not correspond with pre- and post-menopausal status. This is crucial for comparison with other studies. Secondly, a large proportion of cancers $(38 \%)$ were diagnosed within two years of blood donation and the median 'lead-in time' of 2.5 to 3 years was short compared with other studies (typically 5 to 7 years). Indeed, many studies excluded cases diagnosed within one year of blood donation as it is well established that the presence of a tumour (and presumably also occult disease) may influence IGF-I physiology (Renehan et al. 2000). When this is taken into account, there were positive associations with IGF-I and IGFBP-3 in women under 50 years of age in whom blood donation was greater than two years before the diagnosis of their breast cancer.

The second study expands the contribution of Michael Pollak and his collaborators to the IGF cancer literature focusing on the Nurses Health Study II (Schernhammer et al. 2006). Their main conclusion is that, in this large cohort, 'levels (of IGF-I and IGFBP-3) appear to have no important association with breast cancer risk'. Again, at first glance, these results appear to contradict the main literature. However, in contrast to their previous NHS I study (Hankinson et al. 1998), a larger proportion of the more modern cohort will include screen-detected breast cancers (as reflected by the inclusion of in situ disease). Freedland and colleagues (2006) have convincingly demonstrated in the example of prostate cancer that the prevalence of screening in a population may markedly impact upon cancer risk associations, and this may be pertinent to circulating IGFs and breast cancer risk.

Schernhammer et al. (2006) also determined associations for GH and IGFBP-1, but found no significant associations. Due to the circadian changes in $\mathrm{GH}$ and the general poor sensitivity of many $\mathrm{GH}$ assays, this is not an 'epidemiology friendly' hormone, and the lack of associations is not surprising. Furthermore, whereas $\mathrm{GH}$ is well-correlated with IGF-I in childhood, this is not so in adulthood. On the other hand, IGFBP-1 is an analyte more related to insulin resistance, although it may have a regulatory role in IGF-I bio-availability. Other studies (Krajcik et al. 2002, Muti et al. 2002) have 
similarly found no associations between IGFBP-1 and either pre- or post-menopausal breast cancers.

Against the background of these new studies (Rinaldi et al. 2006, Schernhammer et al. 2006), we have updated our review stratified into pre-menopausal (Hankinson et al. 1998, Toniolo et al. 2000, Krajcik et al. 2002, Muti et al. 2002, Allen et al. 2005, Rinaldi et al. 2005, 2006, Schernhammer et al. 2005, 2006) and post-menopausal (Hankinson et al. 1998, Toniolo et al. 2000, Krajcik et al. 2002, Muti et al. 2002, Keinan-Boker et al. 2003, Gronbaek et al. 2004, Allen et al. 2005, Schernhammer et al. 2005, Rinaldi et al. 2006, Rollison et al. 2006) groups. As the main debate focuses on pre-menopausal and young women, these are presented here (Fig. 1). We used a cumulative random-effects meta-analysis to demonstrate the effect of change with relation to year of publication since 1998. This showed that the association between total IGF-I and the diagnosis of pre-menopausal breast cancer has become attenuated with passing years of publication, although it remains positive and significant (cumulative effect $=1.69(95 \%$ CI: 1.17 , 2.45)). For women with a diagnosis of breast cancer before 50 years of age, the cumulative estimate suggests that the risk is stronger $(2.13(95 \%$ CI: $1.25,3.64)$ ). For pre-menopausal breast cancer and IGFBP-3, this association was positive and significant at the time of our analysis to the end of 2002, but for the up-dated analysis, there is considerable statistical heterogeneity among studies $(P=0.003)$ and the association is now null.

To summarise, the literature to-date indicates that there are no discernible associations between IGF-I, IGFBP-3 and post-menopausal breast cancer risk, that there are modest associations between IGF-I and breast cancer risk in pre-menopausal and young women, and that the main area of controversy is the relationship between IGFBP-3 and pre-menopausal breast cancer risk. To tackle this 'muddy water', there is a compelling need to standardise studies for comparative purposes. First is the problem of study design. The majority of cohort studies to-date determined associations between IGF analytes and breast cancer risk sub-classified into pre- and post-menopausal status at the time of diagnosis, rather than status at blood donation. At least for circulating IGFs and breast cancer risk, this distinction appears to be important and should be based on conventional medical record-based definitions of menopause rather than cut-offs by age group. It is a completely different scenario to design an analysis based on age at recruitment as was reported by Kaaks et al. (2002). Having stated this, it is still an interesting question to ask whether or not there is a relationship between premenopausal status at the time of collection of blood and subsequent post-menopausal breast cancer risk. This was specifically addressed by Rollison et al. (2006) who reported that higher levels of IGF-I in younger women ( 25 to 35 years) at recruitment might predict for subsequent post-menopausal breast cancer, whilst associations with IGFBP-3 were marginally inverse. As sub-group sizes were small, this study needs to be repeated with larger numbers.

The second problem is standardisation of the assays used, and here the debate focuses on IGFBP-3. Under normal conditions, there is an appreciable but variable level of IGFBP-3 serum proteolysis, which, in turn, may impact on the determination of 'total' IGFBP-3 concentrations in the circulation. Schernhammer et al. (2006) state that the radioimmunoassay is the 'gold standard', but this has not been robustly tested in the models of association of cancer risk.

The third problem is that of mutual adjustment of IGF-I and IGFBP-3 within multilevel analyses. Unquestionably, both analytes are well correlated and partly inter-dependent, but the statistical process of mutual adjustment is confusing. In some instances, there are potentiating associations (Hankinson et al. 1998, Allen et al. 2005); in others, attenuating associations (Krajcik et al. 2002, Rinaldi et al. 2006). In addition, reporting models of association based on the IGF-I/IGFBP-3 ratio is misleading as it may be confused with, and is a poor surrogate of, IGF-I bioavailability (Renehan et al. 2006). It seems prudent to report multilevel analyses with and without mutual adjustments in future studies.

Eight years on, the initial excitement about the determination of IGF analytes and the prediction of cancer risk may seem dampened. However, IGF analytes may still be useful markers of response to interventions (Harvie \& Howell 2006), as they are inexpensive, well tested, and robust to variations in blood handling. In an era when peptide biochemists are focused on serum proteomics and metabolomics as predictors of disease, these new technologies are expensive to develop and troubled by reproducibility. Several dietary, lifestyle and pharmacological approaches may favourably modulate IGF physiology, offering untapped opportunities to prevent or modify disease progression in breast cancer and other common adult cancers. 
A G Renehan et al.: IGF-I, IGFBP-3 and cancer risk

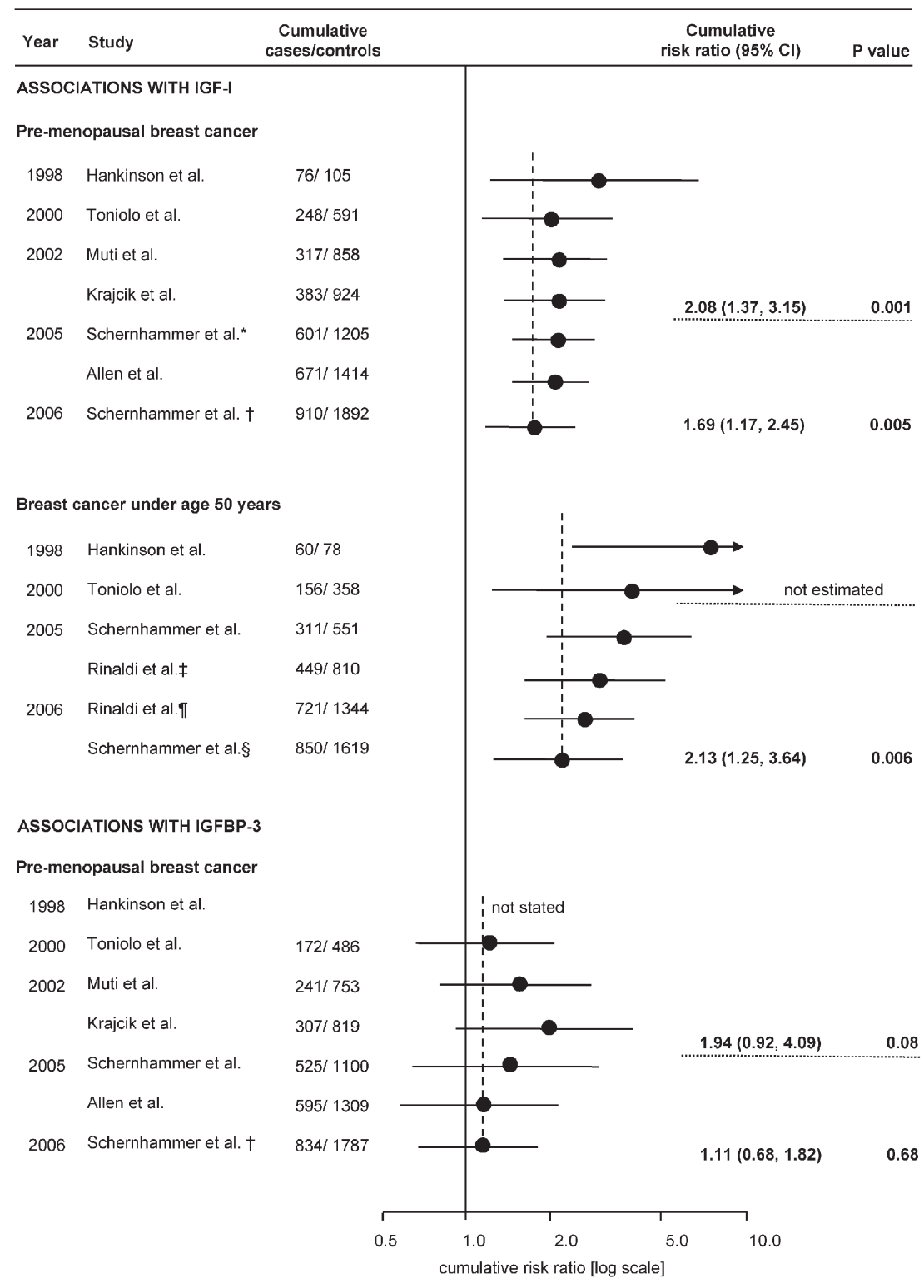

Figure 1 Cumulative meta-analysis of cohort studies comparing associations for highest versus lowest IGF-I and IGFBP-3 categories for pre-menopausal breast cancer, and breast cancer diagnosed in subjects under 50 years of age (for IGF-I only). The literature search described in Renehan et al. (2004) was updated to February 2006. Studies were included using the previously defined criteria with the exception that updated studies were included in order to demonstrate the effect of year of publication and/or updated analysis on summary estimates. The list of excluded studies is available on webappendix 1 . As we had previously shown that case-control studies tended to over-estimate effects, we focused on cohort studies only for this meta-analysis. The cumulative meta-analysis was performed using STATA (version 8.2, College Station, TX, USA). The sequence of the studies has been sorted by year. Within the Forest plots, the continuous vertical line represents unity, the dashed vertical lines represent the mid-point of the cumulative estimate, and the horizontal dashed lines represent the time point of our previous search and review. Full statistical details for IGF-I and IGFBP-3 associations for pre- and post-menopausal and for under 50 years of age are available as a supplemental file (webappendix2).

* Schernhammer et al. (2005): this is an update of Hankinson et al. (1998). † Schernhammer et al. (2006): of the 239 women who were pre-menopausal at blood collection, all but $14(6 \%)$ were still pre-menopausal at diagnosis. $\ddagger$ Rinaldi et al. (2005): this is an extended analysis of young women from Toniolo et al. (2000). - Rinaldi et al. (2006): the odds ratios and their $95 \%$ Cls are those reported in women with a diagnosis of breast cancer under 50 years of age and collected more than 2 years prior to diagnosis. $\S$ Schernhammer et al. (2006): these women were pre-menopausal and under 45 years of age.

Webappendices: http://christie.man.ac.uk/profinfo/departments/surgery/publications_list.htm 


\section{Potential conflict of interest}

A GR has received hospitality from Diagnostic Systems Laboratories and a lecture honorarium from Eli-Lilly. The authors declare that there is no conflict of interest that would prejudice the impartiality of this scientific work.

\section{References}

Allen NE, Roddam AW, Allen DS, Fentiman IS, Dos Santos Silva I, Peto J, Holly JM \& Key TJ 2005 A prospective study of serum insulin-like growth factor-I (IGF-I), IGF-II, IGF-binding protein-3 and breast cancer risk. British Journal of Cancer 92 1283-1287.

Al-Zahrani A, Sandhu MS, Luben RN, Thompson D, Baynes C, Pooley KA, Luccarini C, Munday H, Perkins B, Smith P, Pharoah PD, Wareham NJ, Easton DF, Ponder BA \& Dunning AM 2006 IGF-I and IGFBP-3 tagging polymorphisms are associated with circulating levels of IGF-I, IGFBP-3 and risk of breast cancer. Human Molecular Genetics 15 1-10.

Baxter RC 2001 What is the significance of IGF-binding protein-3 proteolysis in the circulation? Journal of Clinical Endocrinology and Metabolism 86 5087-5088.

Chan JM, Stampfer MJ, Giovannucci E, Gann PH, Ma J, Wilkinson P, Hennekens CH \& Pollak M 1998 Plasma insulin-like growth factor-I and prostate cancer risk: a prospective study. Science 279 563-566.

Firth SM \& Baxter RC 2002 Cellular actions of the insulinlike growth factor binding proteins. Endocrine Reviews 23 824-854.

Fletcher O, Gibson L, Johnson N, Altmann DR, Holly JM, Ashworth A, Peto J \& Silva Idos S 2005 Polymorphisms and circulating levels in the insulin-like growth factor system and risk of breast cancer: a systematic review. Cancer Epidemiology Biomarkers and Prevention 14 2-19.

Freedland SJ, Giovannucci E \& Platz EA 2006 Are findings from studies of obesity and prostate cancer really in conflict? Cancer Causes Control 17 5-9.

Gronbaek H, Flyvbjerg A, Mellemkjaer L, Tjonneland A, Christensen J, Sorensen HT \& Overvad K 2004 Serum insulin-like growth factors, insulin-like growth factor binding proteins, and breast cancer risk in postmenopausal women. Cancer Epidemiology Biomarkers and Prevention 13 1759-1764.

Hankinson SE, Willett WC, Colditz GA, Hunter DJ, Michaud DS, Deroo B, Rosner B, Speizer FE \& Pollak M 1998 Circulating concentrations of insulin-like growth factor-I and risk of breast cancer. Lancet 351 1393-1396.

Harvie M \& Howell A 2006 Energy balance adiposity and breast cancer - energy restriction strategies for breast cancer prevention. Obesity Reviews 7 33-47.

Howell A, Sims AH, Ong KR, Harvie MN, Evans DG \& Clarke RB 2005 Mechanisms of disease: prediction and prevention of breast cancer - cellular and molecular interactions. Nature Clinical Practice Oncology 2 635-646.
Kaaks R, Lundin E, Rinaldi S, Manjer J, Biessy C, Soderberg S, Lenner P, Janzon L, Riboli E, Berglund G \& Hallmans G 2002 Prospective study of IGF-I, IGFbinding proteins, and breast cancer risk in northern and southern Sweden. Cancer Causes and Control 13 307-316.

Keinan-Boker L, Bueno De Mesquita HB, Kaaks R, Van Gils CH, Van Noord PA, Rinaldi S, Riboli E, Seidell JC, Grobbee DE \& Peeters PH 2003 Circulating levels of insulin-like growth factor I, its binding proteins $-1,-2,-3$, $\mathrm{C}$-peptide and risk of postmenopausal breast cancer. International Journal of Cancer 106 90-95.

Krajcik RA, Borofsky ND, Massardo S \& Orentreich N 2002 Insulin-like growth factor I (IGF-I), IGF-binding proteins, and breast cancer. Cancer Epidemiology Biomarkers and Prevention 11 1566-1573.

McCaig C, Perks CM \& Holly JM 2002 Intrinsic actions of IGFBP-3 and IGFBP-5 on Hs578T breast cancer epithelial cells: inhibition or accentuation of attachment and survival is dependent upon the presence of fibronectin. Journal of Cell Science 115 4293-4303.

Muti P, Quattrin T, Grant BJ, Krogh V, Micheli A, Schunemann HJ, Ram M, Freudenheim JL, Sieri S, Trevisan M \& Berrino F 2002 Fasting glucose is a risk factor for breast cancer: a prospective study. Cancer Epidemiology Biomarkers and Prevention 11 1361-1368.

Renehan AG 2004 Cancer risk and the growth hormone/ IGF-I axis. In Pituitary Function through the Ages, HypoCCS Series, vol 8, pp 143-177. Eds R Ross \& EM Erfurth. Bristol: BioScientifica Ltd.

Renehan AG, Jones J, Potten CS, Shalet SM \& O’Dwyer ST 2000 Elevated serum insulin-like growth factor (IGF)-II and IGF binding protein-2 in patients with colorectal cancer. British Journal of Cancer 83 1344-1350.

Renehan AG, Zwahlen M, Minder C, O'Dwyer ST, Shalet SM \& Egger M 2004 Insulin-like growth factor (IGF)-I, IGF binding protein-3, and cancer risk: systematic review and meta-regression analysis. Lancet 363 1346-1353.

Renehan AG, Egger M, Minder C, O’Dwyer ST, Shalet SM \& Zwahlen M 2005a IGF-I, IGF binding protein-3 and breast cancer risk: comparison of 3 meta-analyses. International Journal of Cancer 115 1006-1007.

Renehan AG, Zwahlen M, Egger M \& Shalet SM $2005 b$ Circulating IGF-I, IGFBP-3 and breast cancer risk. Breast Cancer Online (www.bco.org) 8.

Renehan AG, Frystyk J \& Flyvbjerg A 2006 Obesity and cancer: the role of IGF-I and insulin. Trends in Endocrinology and Metabolism (In Press).

Ricort JM \& Binoux M 2004 Insulin-like growth factor binding protein-3 stimulates phosphatidylinositol 3kinase in MCF-7 breast carcinoma cells. Biochemical and Biophysical Research Communications 314 1044-1049.

Rinaldi S, Kaaks R, Zeleniuch-Jacquotte A, Arslan AA, Shore RE, Koenig KL, Dossus L, Riboli E, Stattin P, Lukanova A \& Toniolo P 2005 Insulin-like growth factor-I, IGF binding protein-3, and breast cancer in young women: a comparison of risk estimates using different peptide assays. Cancer Epidemiology Biomarkers and Prevention 14 48-52. 
Rinaldi S, Peeters PH, Berrino F, Dossus L, Biessy C, Olsen A, Tjonneland A, Clavel-Chapelon F, Boutron-Ruault MC, Tehard B et al. 2006 IGF-I, IGFBP-3 and breast cancer risk in women; the European Prospective Investigation into Cancer and Nutrition (EPIC). Endocrine-Related Cancer 13 593-605.

Rollison DE, Newschaffer CJ, Tao Y, Pollak M \& Helzlsouer KJ 2006 Premenopausal levels of circulating insulin-like growth factor I and the risk of postmenopausal breast cancer. International Journal of Cancer 118 1279-1284.

Schernhammer ES, Holly JM, Pollak MN \& Hankinson SE 2005 Circulating levels of insulin-like growth factors, their binding proteins, and breast cancer risk. Cancer Epidemiology Biomarkers and Prevention 14 699-704.
Schernhammer ES, Holly JM, Hunter DJ, Pollak MN \& Hankinson SE 2006 Insulin-like growth factor-I, its binding proteins (IGFBP-1 and IGFBP-3), and growth hormone and breast cancer risk in the Nurses Health Study II. Endocrine-Related Cancer 13 583-592.

Toniolo P, Bruning PF, Akhmedkhanov A, Bonfrer JM, Koenig KL, Lukanova A, Shore RE \& Zeleniuch Jacquotte A 2000 Serum insulin-like growth factor-I and breast cancer. International Journal of Cancer $\mathbf{8 8}$ 828-832.

Wu Y, Cui K, Miyoshi K, Hennighausen L, Green JE, Setser J, LeRoith D \& Yakar S 2003 Reduced circulating insulin-like growth factor I levels delay the onset of chemically and genetically induced mammary tumors. Cancer Research 63 4384-4388. 